\title{
Classification of Breast Cancer Cells on the Basis of a Functional Assay for Estrogen Receptor
}

\author{
Debajit K. Biswas, Lidia Averboukh, Shijie Sheng, \\ Kathy Martin, Darren S. Ewaniuk, Teddy F. Jawde, \\ Feilan Wang, and Arthur B. Pardee \\ Division of Cancer Biology, Dana-Farber Cancer Institute and Harvard \\ Medical School, Boston, Massachusetts, U.S.A.
}

Communicated by A. Pardee. Accepted May 29, 1998.

\begin{abstract}
Background: The receptor (ER) for estrogen (E2) is routinely assayed as a marker to determine the feasibility of anti-hormone therapy against breast cancer because $\mathrm{ER}$-positive $(\mathrm{ER}+)$ tumors are much more likely to respond to anti-hormone therapy than are ER-negative (ER-). However $40 \%$ of ER+ breast cancer patients do not respond to anti-hormone therapy. We suggest that this unpredictability of therapeutic responses lies in the current ER assays, which measure only an initial component of the E2-responsive pathway, and that the difference depends upon altered downstream processes. We propose a functional criterion that subclassifies breast cancers on the basis of specific binding of ER to its cognate DNA sequence, the estrogen response element (ERE).

Materials and Methods: ER was identified in breast cancer cell lines by immunofluorescence assay, Western blot analysis, identification of ER-specific MRNA, and by interaction of the ER-ERE complex with three different ER-specific antibodies. ER-ERE complex formation was measured by electrophoretic mobility shift assay (EMSA). Transactivation of the E2-responsive gene was studied by transfection of cells with fusion gene construct
\end{abstract}

with the promoter-containing ERE sequence and assay of reporter gene activity in the cell extracts.

Results: The growth of ER+ T47D cells was sensitive to tamoxifen, ICI-182,780, and ethynyl estradiol (EE2), whereas another ER+ breast cancer cell line, 21PT, was resistant to these compounds. The estrogen receptor (ER) in the nuclear extracts of MCF-7 and T47D demonstrated hormone-dependent interaction with the response element (ERE) and also downstream transactivation of the E2-responsive PS2 promoter. But in the 21PT cell line that was designated as ER- on the basis of ligand-binding assay and was found to be ER+ by all the other ER assays, ER-ERE interaction and PS2 promoter transactivation were independent of hormone.

Conclusions: On the basis of the downstream functional assay of ER interaction with ERE, ER+ breast tumor cells can be subclassified into two categories. The first is E2-dependent $\left(\mathrm{ER}^{d}+\right)$ and these cells should respond to anti-hormone therapy. The second type of ER interacts with ERE independent of E2 $\left(\mathrm{ER}^{i}+\right)$ and constitutively transactivates responsive genes. It is predicted that the latter type of breast cancers will not respond to antihormone therapy.

\section{Introduction}

The growth of many breast cancers is affected by hormones, more specifically by estrogen (E2) and progesterone (1-16). These hormones bind to their protein receptors (ER and PR), which regulate responsive genes via specific proteinDNA interactions (7-10). ER and PR are routinely assayed as clinical markers to determine feasibility of applying anti-hormone therapy (11-13). Breast cancers measured conventionally are two-thirds ER+, having 100-300 fmol $\mathrm{ER} / \mathrm{mg}$ of cytosol protein, and one-third $\mathrm{ER}^{-}$ with normal breast epithelial cells having 0-37 $\mathrm{fmol} / \mathrm{mg}$ of cytosol protein $(14,15)$. Many ER+ cancers are responsive to anti-estrogens such as tamoxifen (TAM) (16). But $40 \%$ of the ER+ tumors do not respond, nor generally do $\mathrm{ER}^{-}$ 
tumors (17). This may be due to tumor heterogeneity or to mutations that generate ERs whose function is ligand-independent, superfunctional, or bypassed (18-22). The ER phenotype is currently defined by either ligand binding or ERspecific antibody assays. ER variants with defective ligand or antibody binding may not be detected by these assays $(18,19)$. Therefore, a more informative and simple test for predicting tumor responsiveness to anti-hormone therapy would be valuable. This assay would be important because hormone therapy is the first line of defense if it is applicable (23).

The action of E2 is initiated with its binding to the hormone-specific receptor (ER), followed by dimerization of ER, phosphorylation, and a change from an inactive to active state (2-7). The dimerized protein interacts with short palindromic DNA sequences designated estrogen response element (ERE), and it activates estrogenresponsive genes (24). Several other proteins are reported to be involved in both ER-ERE interaction $(5,25-26)$ and the downstream event of specific promoter activation (5-7,24,27-30). Transcriptional activity of ER is more complex in some cases. It can depend on sequences other than the consensus ERE (31), and ER even transactivates the brain creatine kinase gene that lacks an ERE, which is apparently mediated by protein-protein interactions involving ER and molecules capable of interacting directly with this promoter (32). The identification of another class of ER (ER- $\beta$ ) adds a new dimension to the molecular mechanism of E2-ER pathway transactivation of genes $(33,34)$.

An altered functional status of ER in ER+ cells may be due to defects in any one or more of the steps of the multistep ER-response pathway (35). Mutations undetected by current ER assays can have a major impact on ER's role, such as binding to ligand, binding to ERE, modulation of expression pattern of hormone responsive genes, and for anti-hormone responsiveness. Thus it is no surprise that the standard ER assays do not discriminate well between tumors that are or are not responsive to anti-estrogen therapy. Assays

Lidia Averboukh's current address is Ergo Science, 100 First Avenue, Charlestown, Boston, MA 02124. Feilan Wang's current address is Smith Kline Beecham Pharmaceutical Corporation, 707 Swedeland Road, Philadelphia, PA 19406-0939

Address correspondence and reprint requests to: Debajit K. Biswas, Division of Cancer Biology, Dana-Farber Cancer Institute, 44 Binney Street, Boston MA 02115, U.S.A. Phone: 617-632-4684; Fax: 617-632-4680; E-mail: biswas@mbcrr.harvard.edu of function are required to make this clinically important distinction. Our results on ER status, using ER-ERE DNA-binding assays with breast cancer cell lines, provide useful information that could not be obtained by conventional assays.

\section{Materials and Methods}

\section{Materials}

Synthetic single-stranded complementary oligonucleotides containing the wild type (5' GTCCAAAGTCAGGTCACAGTGACCTGATCAAAGTT 3') or single (M1 5' GTCCAAAGTCAGGACACAGTGACCTGATCAAAGTT 3') or double (M2 5' GTCCAAAGTCAGGACACAGTGTCCTGATCAAAGTT 3') mutations (indicated by the underlined bases) in the ERE sequence were obtained from Gibco-BRL. 17 $\beta$ estradiol (E2), hydrocortisone, insulin, tamoxifen, $17 \alpha$-ethynylestradiol, dithiothreitol, dimethyl sulfoxide, and phenylmethylsulfonyl fluoride were from Sigma Chemicals (St. Louis, MO). ICI182,780 was obtained from Dr. M. Brown of DanaFarber Cancer Institute. The fusion plasmid PS2CAT was obtained as gifts from Dr. P. Chambon (36) of Strasbourg, France, and pERE-TK-CAT (37) from Dr. M-J. Tsai of Baylor Medical School, Houston, TX. Purified human recombinant ER was obtained from Pan Vera Corp. (Madison, WI). The ECL immunodetection kit was from Amersham Life Sciences.

\section{Cell Lines and Culture}

MCF-7, T47D, and MDA 231 cell lines were obtained from ATCC. The 70N normal cells in culture were obtained from Dr. R. Sager's collection (38). These cells, characterized as being of myoepithelial origin, are not immortal and can be grown only for about 20 passages in culture. A sample frozen at early passage was grown under standard tissue culture conditions as described below and was used for this study. The 21PT cell line was established in Dr. Sager's laboratory from a primary breast tumor and characterized as ER - on the basis of the ligand binding assay $(38,39)$. MS cells: Recently established $\mathrm{ER}^{+}$ breast cancer cells in culture from the secondary growth in brain.

Cells were grown in rich medium (DMEM supplemented with $10 \%$ FBS and $2.8 \mu \mathrm{M}$ hydrocortisone, $1 \mu \mathrm{g} / \mathrm{ml}$ insulin, and $12.5 \mathrm{ng} / \mathrm{ml} \mathrm{EGF)}$ at $37^{\circ} \mathrm{C}$ in $5 \% \mathrm{CO}_{2}$ and $95 \%$ air. For hormone response studies, dextran-coated charcoal (DCC) 
medium (DMEM without phenol red) supplemented with $10 \%$ stripped serum (DCC-treated FBS to reduce the $\mathrm{E} 2$ level in the serum to $10^{-12}$ $M$, Hyclone) was used. Further supplementation of DCC medium is indicated in the legends to figures or tables illustrating specific experiments.

\section{Electrophoretic Mobility Shift Assay (EMSA)}

ER-ERE interaction was measured using EMSA by incubating nuclear extracts (40) from cells with ${ }^{32}$ P-labeled double-stranded synthetic oligonucleotides (shown above) under conditions described by Kumar and Chambon (24). One nanogram (approximately 30,000 CPM) of ${ }^{32} \mathrm{P}$ labeled double-stranded oligonucleotide with palindromic ERE (as shown above) was used per reaction and incubated $30 \mathrm{~min}$ at room temperatures. The reaction mixture was then subjected to nondenaturing polyacrylamide gel $(6 \%)$ electrophoresis (PAGE) and the protein-DNA complex was detected by autoradiography of the dried gel as described previously $(41,42)$. ER monoclonal antibodies used were ER-Ab-1, raised against aminoacid residues $120-170$ of the $\mathrm{N}$-terminal transactivation domain of calf uterus estrogen receptor; TEl-11, raised against amino acid residues $300-595$ of the $\mathrm{C}$-terminal region of human ER (Neo Markers, Fremont, CA); and SRA 1010, raised against amino acid residues 582-595 of the C-terminal region of human ER (Neo Markers, Fremont, CA); and SRA 1010, raised against amino acid residues 582-595 of the C-terminal region of human ER (Stress Gen, BC, Canada).

\section{Immunofluorescent Staining of Estrogen Receptor}

Cells cultured in chamber slides for $24 \mathrm{hr}$ were washed with phosphate-buffered saline (PBS) and fixed with $4 \%$ paraformaldehyde, permeabilized with PBS containing $0.2 \%$ Triton X-100, and stained following a standard protocol (43). Undiluted culture medium of hybridoma clone TE1-11 was used as the primary antibody against ER. The secondary antibody was 100 -fold diluted goat anti-mouse IgG (whole molecule) conjugated with FITC. Duplicate samples of each of these cell lines, processed similarly by using mouse IgG as primary antibody, served as controls for nonspecific signals.

\section{Western Blot Analysis}

Cells were grown in rich medium as described above. Cell extracts were prepared with a lysis buffer (62.5 mM Tris-HCl, pH 6.8, 0.5\% NP-40, $10 \%$ glycerol, $1 \mathrm{mM}$ PMSF, $5 \mu \mathrm{g} / \mathrm{ml}$ aprotinin, and $10 \mu \mathrm{g} / \mathrm{ml}$ leupeptin). Aliquots of lysates with the same amount of protein were fractionated by SDS-PAGE followed by electroblotting to a nitrocellulose membrane. Immunoblot analysis was performed with a human monoclonal anti-ER antibody (SRA 1010, StressGen, Victoria, BC, Canada) followed by incubation with the secondary goat anti-mouse IgG-HRP conjugate and was immunodetected with an enhanced chemiluminescence system (ECL, Amersham Life Sciences). No signals were detected in the duplicate blot with the same samples when processed with mouse IgG as primary antibody.

\section{Northern Blot Analysis}

RNAs from indicated cells were isolated by following the standard protocol (44). Gel analysis, transfer to membrane, prehybridization, and hy bridization conditions were as described in this protocol (44). The cDNA-ER was ${ }^{32}$ P-labeled using the random-primed DNA labeling kit (Boehringer Mannheim, Indianapolis), and $10^{6}$ $\mathrm{CPM} / \mathrm{ml}$ of this radioactive cDNA-ER was used for hybridization.

\section{Transfection Studies}

Transient transfection of MCF-7 and 21PT cells with either the fusion plasmid PS2-CAT (36) or pERE-TK-CAT (37) was performed using the DEAE dextran procedure as described previously 42). Conditions for cell growth, E2 treatment, and chloramphenicol acetyl transferase (CAT) assays are described in the legend to Figure 6.

\section{Differential mRNA Display Technique (DD)}

Differential gene expression in E2-treated MCF-7 and 21PT cells was studied by the DD technique (45) using arbitrary HAP-5 and HAP-6 and anchor primers of the GenHunter Kit (Vanderbilt, TN) as described previously. Cell growth, E2 treatment conditions, and RNA isolation are described in the legend to Table 1. To further characterize the specific differentially expressed genes, DNA from excised DD bands was eluted (45) and directly sequenced (46) using a manual cycle sequencing kit (Circum Vent, New England BioLabs). Sequencing reactions were primed with the appropriate arbitrary DD 10mer at an annealing temperature of $45^{\circ} \mathrm{C}$. The sequences obtained were queried against the 
Table 1. Identity, verification, and E2-dependent expression pattern of gene tags isolated by DD from breast cancer cell lines

\begin{tabular}{|c|c|c|c|c|c|c|}
\hline & \multirow[b]{2}{*}{$\begin{array}{l}\text { Band } \\
\mathrm{ID}^{a}\end{array}$} & \multirow[b]{2}{*}{ Gene ID } & \multirow[b]{2}{*}{$\mathrm{EST} \mathrm{ID}^{b}$} & \multirow[b]{2}{*}{$\begin{array}{l}\text { Readable Direct } \\
\text { Sequence }^{c}\end{array}$} & \multicolumn{2}{|c|}{$\begin{array}{l}\text { Expression Pattern in Response } \\
\text { to } \mathrm{E} 2^{d}\end{array}$} \\
\hline & & & & & $\begin{array}{c}\text { MCF-7 } \\
(\mathrm{ER}+)\end{array}$ & $\begin{array}{c}21 \mathrm{PT} \\
(\mathrm{ER}-)\end{array}$ \\
\hline 1 & M2 & New & $\mathrm{gb} / \mathrm{N} 67125$ & Yes & Induced & Constitutive \\
\hline 2 & M3 & $\begin{array}{l}\text { Mitochondrial } \\
\text { replication } \\
\text { origin }\end{array}$ & $\mathrm{gb} / \mathrm{K} 02485$ & Yes & Induced & Constitutive \\
\hline 3 & M4 & New & No match & Yes & Suppressed & Off \\
\hline 4 & M5 & New & No match & Yes & Induced & Constitutive \\
\hline 5 & M6 & Reticulocalbin & $\mathrm{dbj} / \mathrm{D} 42073$ & Yes & Induced & Constitutive \\
\hline
\end{tabular}

${ }^{a} \mathrm{DD}$ bands were cut from the MCF-7 track.

${ }^{b}$ Expressed sequence tag (EST) identification is listed for unknown sequence match entries in EST data base.

${ }^{c} \mathrm{~A}$ readable DNA sequence is defined as one that has approximately $80 \%$ unambiguous bases over a region of at least 100 bases. ${ }^{d} \mathrm{E} 2$ treatment is the same as that described in the legend to Figure 5. RNA was isolated from each of control and treated samples and subjected to the DD protocol using the specified arbitrary HAP5 and HAP6 and anchor primers of the Gene Hunter DD Kit (45). Specific DD bands were cut out of the indicated tracks, DNA isolated, PCR amplified, and subjected to direct sequencing.

NCBI database using the BLAST algorithm (47). A match was defined as approximately $96 \%$ identity of bases over a stretch of 30 bases. Following database verification of sequences, a single nested 20-mer oligonucleotide was designed that would hybridize to the DD fragment just inside the arbitrary primer site (48).

\section{Results}

Viability of Breast Cancer Cells in the Presence of Anti-Hormones

Inability to detect ER in 21PT cells by the ligand-binding assay (38) raised the possibility that ER in this cell line is either truly absent (ER-) or is altered so as to affect E2 binding $\left(\mathrm{ER}^{i}+\right)$. In either case, $21 \mathrm{PT}$ cells should be resistant to anti-hormone, whereas hormone-dependent, $\mathrm{ER}^{d}+, \mathrm{MCF}-7$ and T47D cells should be sensitive to anti-hormones. It is thus necessary to develop another assay that will detect such altered ER in breast cancer cells. We examined cell viability of these breast cancer cell lines grown in the presence of three anti-hormones; tamoxifen, ICI-182,780, and ethenylestradiol (EE2) (Fig. 1). They reduced cell viability of $\mathrm{ER}^{d}+\mathrm{T} 47 \mathrm{D}$ (Fig. 1A) cells, but 21PT cells (Fig. 1B) were resistant to each of these drugs. Although EE2 is
A
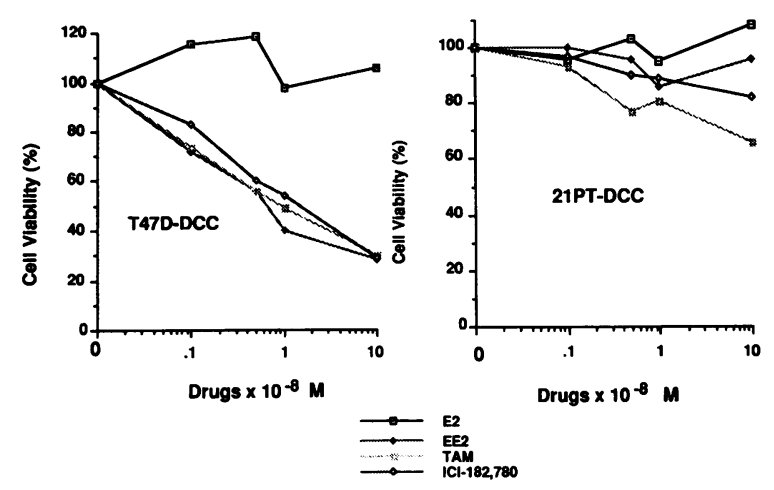

Fig. 1. Anti-hormone sensitivity of T47D and 21 PT cells. T47D (A) and 21 PT $(B)$ cells $\left(1 \times 10^{4}\right)$ were plated in duplicate in 96-well cloning tissue culture dishes either in DMEM medium supplemented with $10 \%$ dextran coated charcoal-treated FBS (DCC), $1 \mu \mathrm{g} / \mathrm{ml}$ insulin and $12.5 \mathrm{ng} / \mathrm{ml} \mathrm{EGF,} \mathrm{or}$ in complete medium (FBS). After $48 \mathrm{hr}$ the medium was removed and fresh DCC medium containing the indicated concentrations of 17- $\beta$ estradiol (E2), ethynylestradiol (EE2), tamoxifen (TAM), or ICI-182,780 were added. The control wells contained the same volume of solvents, $95 \%$ ethanol for E2, EE2, and ICI-182,780, and DMSO for TAM. The medium was changed every 2 days with the same fresh media. After 5 days of treatment, viability of cells was determined by the MTT assay (54). The percent viability of cells in the presence of the antihormones was expressed as percentage of the untreated control. This experiment was repeated twice. 
believed to be an E2 agonist, it showed an antiproliferative effect on $\mathrm{ER}^{d}+\mathrm{T} 47 \mathrm{D}$ cells. This may be caused by the as-yet unknown mechanism by which another estrogen agonist, diethylstilbesterol, shows similar antiproliferative effects on breast cancer cells (2). Such E2 agonsits may be classified as mixed agonists, similar to those such as tamoxifen, that show both antiproliferative and proliferative effects on breast cancer cells (4). When grown in DCC medium supplemented with insulin and EGF, E2-induced stimulation of cell proliferation was not detected. However, inhibitions by the two anti-hormones were observed.

\section{ER-Protein Determined by Immunofluorescent and Western Blot Technique}

The ER protein levels in several breast cancer cell lines which were classified as ER + or ER - on the basis of the detection of the receptor protein by the ligand binding assay (39) were re-examined by immunofluorescence with a monoclonal anti-ER (TEl-11) as primary antibody and goat anti-mouse IgG conjugated to horseradish peroxidase (HRP) as secondary antibody. Mouse IgG (whole molecule) was used as a primary antibody in the control experiments. This assay confirmed the breast cancer cell lines MCF-7 and T47D as ER+, but the $21 \mathrm{PT}$ cell line that was classified as ER - by ligand-binding assay $(38,39)$ was reclassified as ER + by immunofluorescence assay (Fig. 2B). The ER level determined by this assay was much lower in $21 \mathrm{PT}$ cells than in MCF-7 and T47D cells. ER was not detected in $70 \mathrm{~N}$, which is of myoepithelial origin and derived from normal breast tissues, nor in MDA 231 cells, in which ER protein was not detected and is defined as $\mathrm{ER}^{i}-$; ER served as negative control (Fig. 2B).

\section{ER-Protein}

ER in these cell lines was also examined by Western blot analysis using an ER-specific antibody raised against the $\mathrm{C}$-terminal region of the receptor (SRA 1010, aa 582-595) (Fig. 2C). A distinctive band in the size range of ER protein $(68 \mathrm{kD})$ was seen in 21PT cells and was weaker than that observed in MCF-7 and T47D cells. Extracts from ER - cell line MDA231 gave only a difuse background signal (Fig. 2C). Similar analysis of these extracts using mouse IgG as primary antibody also did not give any signals (data not shown).

\section{ER-specific mRNA Levels}

The presence of ER in the 21PT cells was further examined by measurement of ER-specific mRNA by Northern blot analysis of total cellular RNA. A cDNA-ER hybridizable RNA sequence was detected in 21PT cells (Fig. 2D, lane 3 ) in the size range of $6.3 \mathrm{~Kb}$, similar to those observed with total RNA from T47D (lane 1) and MCF-7 (lane

\footnotetext{
Fig. 2. Detection of $E R$ in breast cancer cells in culture by immunofluorescent technique, Western blot, and Northern blot analysis. (A, B) Immunofluorescent technique. Cells were grown in tissue culture chamber slides in complete medium (DMEM supplemented with 10\% FBS, $2.8 \mu \mathrm{M}$ hydrocortisone, $1 \mu \mathrm{g} / \mathrm{ml}$ insulin, and $12.5 \mathrm{ng} / \mathrm{ml}$ of EGF). A standard immunofluorescent technique was used with a monoclonal antibody (TEl-11) as described in Materials and Methods. 70N, cultured cells from normal breast tissue; MCF-7, ER+; 21 PT, ER-; T47D, ER+; and MDA-231, ER-, as measured by ligand-binding assay $(38,39)$. (A) Staining of nuclei by Hoechst. (B) Immunostaining by ER Mab shows positive signals in MCF-7, 21PT, and T47D and no visible immunofluorescent signals in $70 \mathrm{~N}$ and MDA 231. The low-level immunofluorescent signals in 21 PT cells were consistently observed in three separate experiments; thus $21 \mathrm{PT}$ can be reclassified as ER +. (C) ER protein level as determined by Western blot analysis and enhanced chemiluminescence (ECL) immunodetection system by using a monoclonal human anti-ER-antibody as primary antibody (SRA 1010, Stress Gen, Victoria, Canada). The mo-

bility of 70 and $60 \mathrm{kD}$ prestained markers (GibcoBRL) analyzed simultaneously with the extracts from the indicated breast cancer cells is shown by arrowheads. This analysis also classified 21PT cells as $\mathrm{ER}+$, confirming the immunofluorescent assay. A control blot incubated with equivalent amounts of mouse IgG as primary antibody and goat anti-mouse IgG-HRP conjugate as secondary antibody did not generate any visible signals with extracts from either of these cell lines. (D) ER-specific mRNA as determined by Northern blot analysis. Here $10 \mu \mathrm{g}$ of total cellular RNA from T47D, MCF-7, and 21PT cells was probed with ${ }^{32} \mathrm{P}$-labeled CDNA-ER. Arrows on the right show the mobility of $28 \mathrm{~S}$ and $18 \mathrm{~S}$ RNA. One major and one minor cDNA-hybridizable mRNA species are detected as indicated by the arrows on the left. These mRNA species have a size range similar to that of the previously reported mRNA ER species of $6.3 \mathrm{~kb}$ and $3.7 \mathrm{~kb}$, and they further characterized $21 \mathrm{PT}$ cells as ER+. A photograph of the RNA samples applied in each lane is shown on the right of panel D. These samples served as loading control for the amount of RNA in these lanes. This experiment was repeated twice.
} 


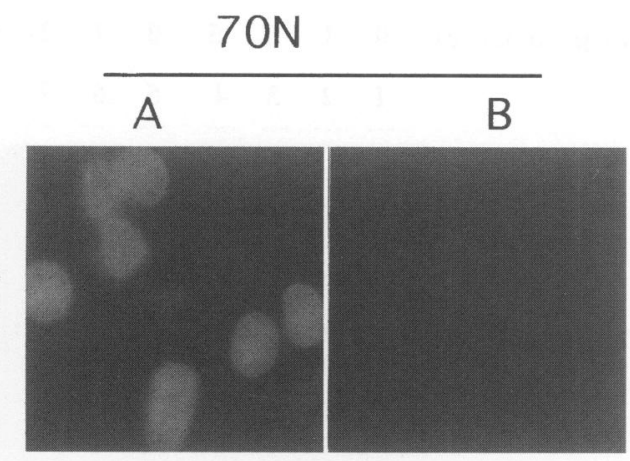

21PT

$$
\text { A }
$$
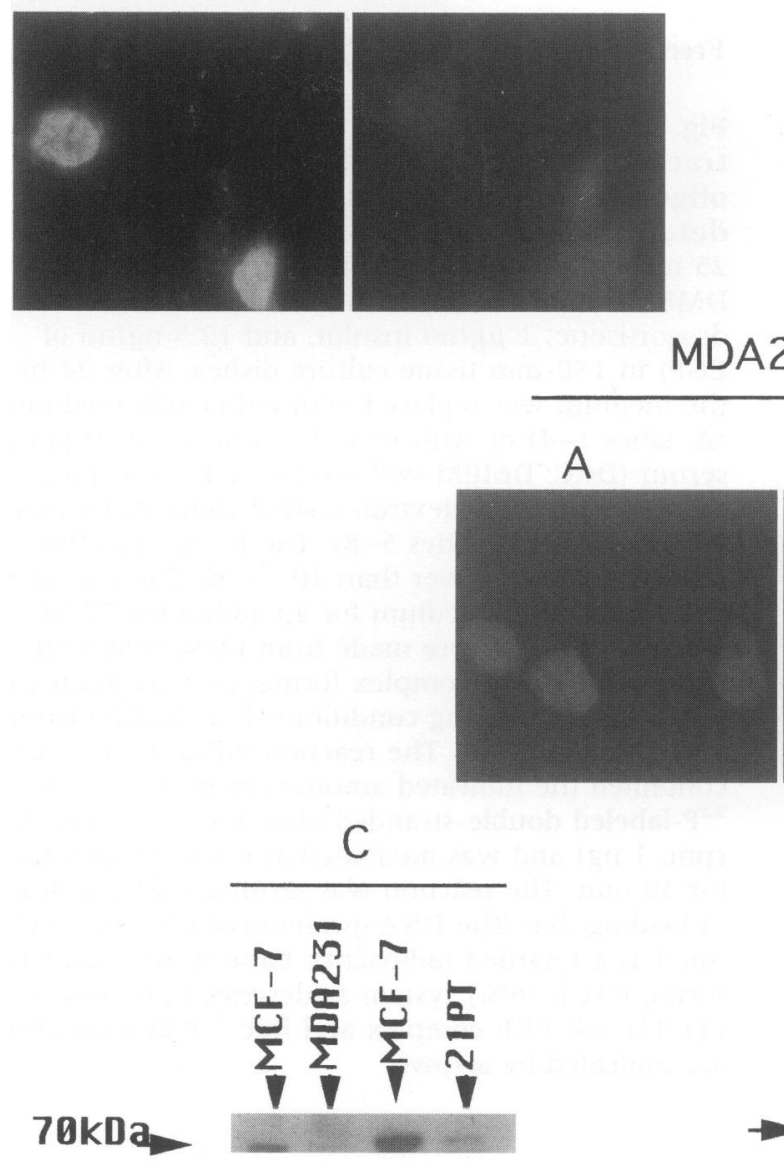

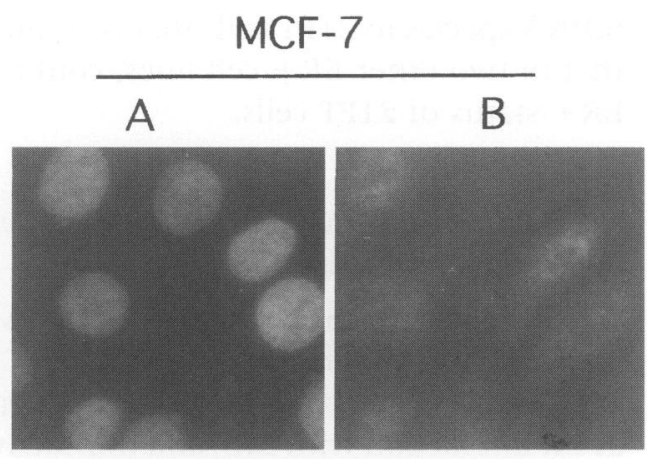

\section{T47D}
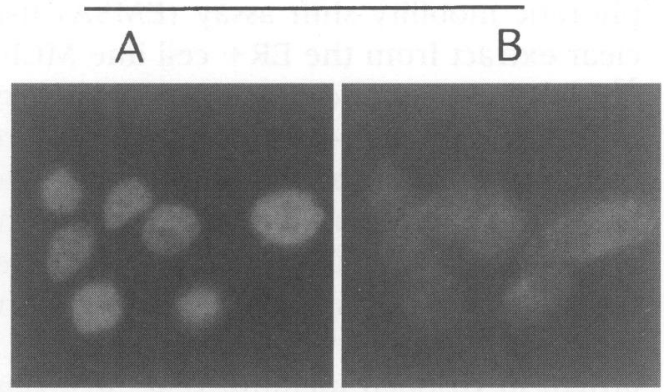

MDA231 
2) cells. A second very weak mRNA band was also detected in RNA preparation of all three cell lines. These results demonstrate an ER-specific mRNA species in 21PT cells that is comparable to that in two other ER+ cell lines, confirming the $\mathrm{ER}+$ status of $21 \mathrm{PT}$ cells.

\section{ER Status in Breast Cancer Cell Lines as Determined by ER-ERE Interaction}

To further establish the identity of ER, we examined its functional status in both MCF-7 and 21PT cells by studying downstream events, such as ER interaction with ERE and transactivation of responsive promoters in the presence or absence of E2. We studied ER-ERE interaction by electrophoretic mobility shift assay (EMSA) using nuclear extract from the ER+ cell line MCF-7 with ${ }^{32} \mathrm{P}$-labeled oligonucleotide carrying the two palindromic ERE half-sites $(24,41,42)$. A retarded band representing a DNA-protein complex similar to the one reported by Kumar and Chambon was detected (24). The DNA protein detected in the nuclear extracts of MCF-7 cells grown in rich medium (Fig. 3A) was greatly reduced in cells grown in stripped medium (Fig. 3B), suggesting that stripped medium is devoid of some component(s), most probably E2, that are required for this process. The ER interaction with ERE is dependent on the presence of hormone and ER in this cell line is classified as $\mathrm{ER}^{d}+$. Addition of E2 to stripped medium stimulated ER binding to ERE (see Fig. 5A).

\section{Identification of ER in the Retarded DNA-Protein Complex}

The identity of ER in the observed retarded band was established by carrying out the binding reaction in the presence of ER-specific antibodies. Three different monoclonal antibodies with epitopes mapping at different domains of ER, as shown in Figure $4 \mathrm{~A}$, were used for these experiments. These monoclonal antibodies are all reactive against human ER. Results shown in Figure $4 \mathrm{~B}$ and $\mathrm{C}$ demonstrated interference of DNA-protein complex formation with nuclear extracts from both MCF-7 and 21PT cells in the presence of each of these three ER-specific antibodies, in contrast to a supershift, which suggests blocking of a reaction site (see Discussion). The order of additions of antibodies, nuclear extracts, and ${ }^{32} \mathrm{P}$-labeled ERE-oligonucleotide in the binding reaction did not influence the results. Preincubation with the same amounts of mouse IgG

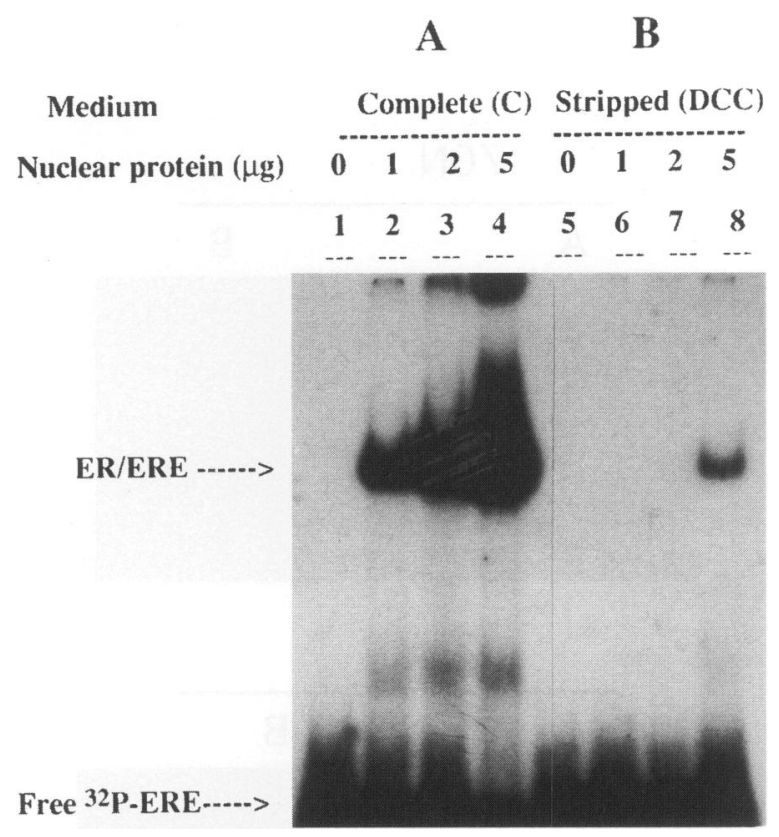

Fig. 3. DNA-protein interaction in nuclear extracts of $E R+M C F-7$ cells in the presence of oligonucleotide carrying palindromic ERE as determined by EMSA. MCF-7 cells were grown in $25 \mathrm{ml}$ of DMEM complete medium (designated as C; DMEM supplemented with $10 \%$ FBS, $2.8 \mu \mathrm{M}$ hydrocortisone, $1 \mu \mathrm{g} / \mathrm{ml}$ insulin, and $12.5 \mathrm{ng} / \mathrm{ml}$ of EGF) in 150-mm tissue culture dishes. After $24 \mathrm{hr}$ the medium was replaced with either rich medium (A, lanes 1-4) or with medium containing stripped serum (DCC; DMEM without phenol red, supplemented with $10 \%$ dextran-coated charcoal-treated FBS, Hyclone; B, lanes 5-8). The E2 level in this treated serum is lower than $10^{-12} \mathrm{M}$. The cells were cultured in DCC medium for an additional $72 \mathrm{hr}$. Nuclear extracts were made from these cells (40) and DNA-protein complex formation was studied by EMSA under binding conditions described by Kumar and Chambon (24). The reaction mixture in $10 \mu \mathrm{l}$ contained the indicated amounts of proteins and

${ }^{32} \mathrm{P}$-labeled double-stranded oligonucleotide $(30,000$ $\mathrm{cpm}, 1 \mathrm{ng}$ ) and was incubated at room temperature for $30 \mathrm{~min}$. The reaction was terminated by addition of loading dye. The DNA-protein complex was identified as a retarded radioactive band in the nondenaturing PAGE $(6 \%)$ system as described previously $(41,42)$. ER-ERE complex and free ${ }^{32} \mathrm{P}$-labeled probe are indicated by arrows.

(whole molecule) or in the presence of the antibody raised against an unrelated protein, p50 subunit of NF- $\kappa \mathrm{B}$, did not significantly reduce the intensities of the retarded band (Fig. 4B), establishing that this complex is due to specific interaction of ER of the nuclear extracts of MCF-7 and 21PT cells with the ERE sequences in the ${ }^{32} \mathrm{P}$-oligonucleotide. Although none of these 
antibodies is raised against the DNA-binding domain, they blocked ER interaction with its motif.

The above results established the identity of ER in the retarded band observed in EMSA. The specificity of ERE in this interaction was first established by competition experiments with wild-type, nonradioactive, ERE-containing oligonucleotides. Nonradioactive ERE-oligonucleotide competed with the ${ }^{32} \mathrm{P}$-ERE oligonucleotide for complex formation, but single (M1) or two base-pair mutations (M2) in the half-sites of the nonradioactive ERE-oligonucleotide did not affect the formation of the radioactive proteinDNA complex even at 10 -fold higher concentrations, verifying specificity of this ER-ERE interaction. The specificity of ER-ERE interaction was further examined by direct binding studies with ${ }^{32} \mathrm{P}$-labeled oligonucleotide carrying single base-pair or two base-pair mutations in the ERE sequence. The mutated EREs did not form any DNA-protein complex with ER in the nuclear extract from MCF-7 cells, whereas the wild-type ERE did form such a complex (data not shown).

\section{Hormone Dependency of ER-ERE Interaction}

We used nuclear extracts from MCF-7, T47D, $21 \mathrm{PT}$, and MS cells grown in DCC medium for 72 $\mathrm{hr}$ in the absence or presence of E2 for the final $2 \mathrm{hr}$ at the indicated concentrations. ER-ERE complex formation detected by EMSA as a retarded band in the nuclear extracts of MCF-7 (Fig. 5A) and T47D (Fig. 5D) was dependent on treatment of the cells with E2, suggesting that hormone binding to the receptor in these pretreated cells is a prerequisite for the downstream function of ER binding to ERE. These results confirmed the $E 2^{d}+$ phenotype of these cells. EMSA analysis of the cytoplasmic fraction of E2treated or untreated cells did not generate a visible retarded band, which suggests that the loss of ER-ERE interaction in the absence of E2 was not due to sublocalization of ER in the cytoplasm (data not shown), substantiating the current concept that ER is localized mostly in the nucleus (9). But this ER-ERE interaction in the nuclear extracts from both 21PT (Fig. 5B) and MS (Fig. 5C) cells was independent of hormone treatment; this suggests that the E2 interaction was not essential for the binding of ER with ERE. Thus 21PT and MS cells can be classified as hormone-independent $\left(\mathrm{ER}^{i}+\right)$. This constitutive interaction suggests that the receptor molecule or an accessory component of the active ER-ERE complex is structurally modified in $\mathrm{ER}^{i}+, 21 \mathrm{PT}$, and MS cells.

The level of ER protein and ER-specific mRNA as determined by immunofluorescent, Western blot, and Northern blot techniques is much higher in ER+ MCF-7 cells than in ER+ 21 PT cells, whereas the intensity of the retarded band representing the ER-ERE complex is much higher in 21PT cells. This suggests a stronger binding affinity of ER to ERE on account of an altered structure of the receptor molecule or the auxiliary binding proteins.

\section{Transactivation of E2-Responsive Genes in MCF-7 and 21PT Cells}

The activation of most of the E2-responsive genes is a consequence of ER-ERE interaction. The PS2 gene is commonly observed to be overexpressed in breast tumors and is E2 responsive (17). The PS2 promoter region is well characterized, and it has been established that the palindromic EREs are solely responsible for ER-mediated upregulation of this hormone-responsive gene (36). We compared transactivation of the PS2 promoter in MCF-7 and 21PT cells by transient transfection of a fusion gene construct, PS2CAT, to cells grown in the absence or presence of E2, followed by measurement of expression of the reporter CAT gene in cell extracts $(24,42)$. This CAT activity was dependent on the concentration of E2 in the growth medium of MCF-7 $\left(\mathrm{ER}^{d}+\right)$ cells (Fig. 6A), whereas it was constitutively up-regulated, even in the absence of $\mathrm{E} 2$, in 21PT (ER $\left.{ }^{i}+\right)$ cells (Fig. 6B). Thus this E2-mediated transactivation pattern strictly correlated with the ER-ERE interactions in these two ER+ breast cancer cell lines as hormone dependent in MCF-7 and hormone independent in 21PT cells.

To substantiate this conclusion we examined the E2-regulated expression of cellular genes by monitoring their levels of expression in MCF-7 and 21PT cells as a function of E2 treatment. With the mRNA differential display technique (45) we detected at least five genes that were similarly expressed or suppressed in a hormonedependent fashion in MCF-7 cells and in a hormone-independent fashion in 21PT cells (Table 1). These results demonstrate that not only that the expression of a transfected gene is hormone dependent or hormone independent in ER+, MCF-7 and 21PT cells, respectively (Fig. 6), but also that the expression of five cellular genes show similar patterns of hormone dependency or independency in these two cell lines. Direct se- 


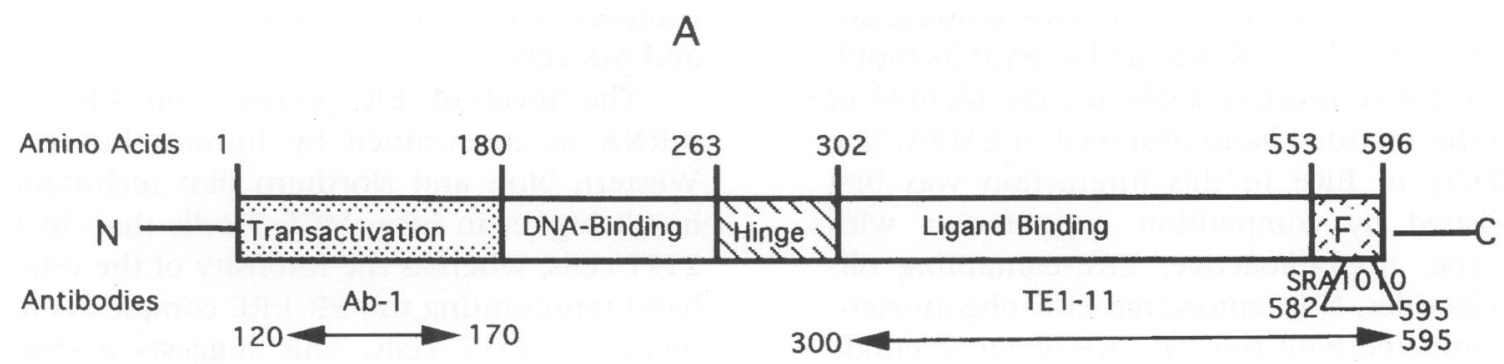

B

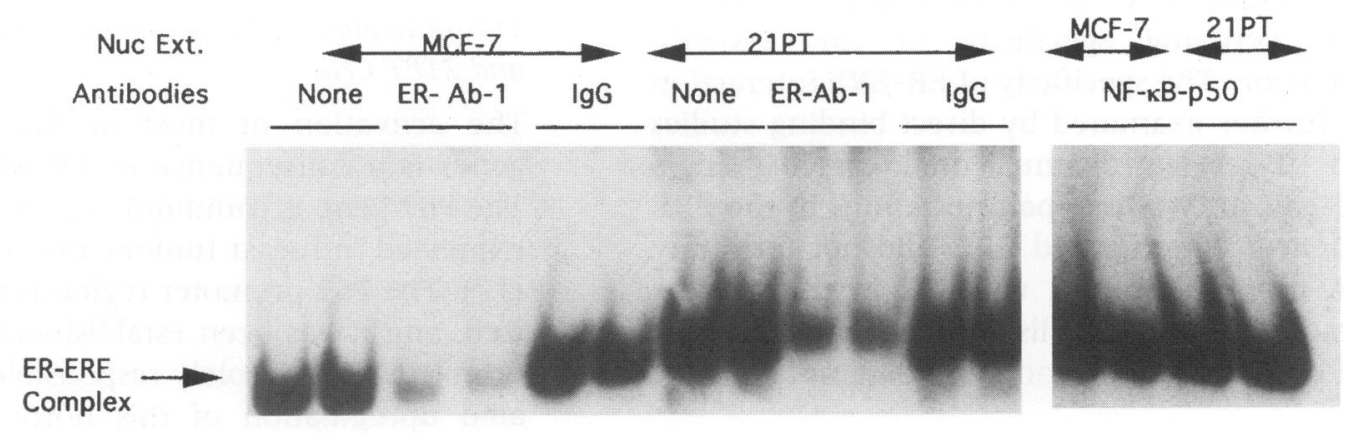

C

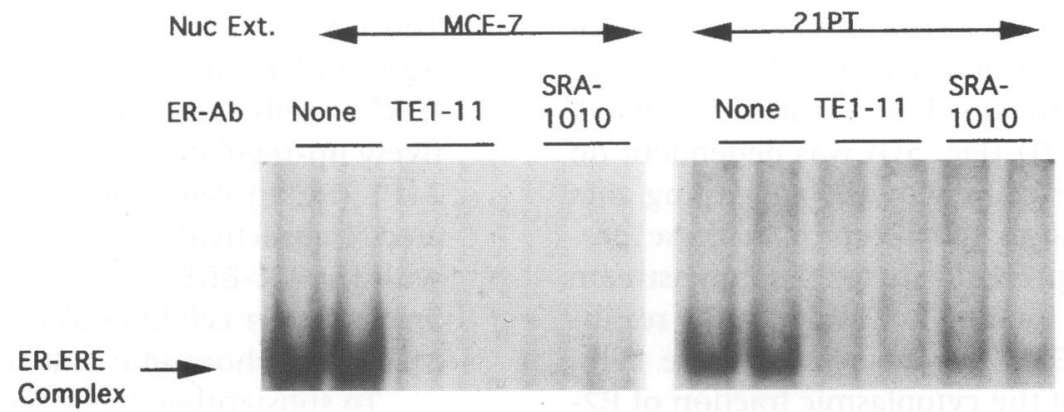

Fig. 4. Influence of anti-ER antibodies on the DNA-protein complex formation in MCF-7 and 21 PT cells. MCF-7 and 21 PT cells were grown in complete medium as described in the legend to Figure 3. Nuclear extracts were prepared, and protein content was measured and subjected to EMSA as described in Figure 3. (A) The structural and functional domains of ER. The epitope maps of the three ER-antibodies used in this experiment are shown below the sketch, details of the ER-antibodies are described in the Materials and Methods. (B) The influence of ER-Ab-1, mouse IgG, and anti-NF- $\kappa$-p50 antibody (rabbit polyclonal IgG raised against 15 amino acid residues mapping at the NLS region of NF- $\kappa \mathrm{B}-\mathrm{p} 50$, mouse, rat, and human reactive, Santa Cruz Biotechnology, Santa Cruz, CA). Binding reaction conditions were the same as described above.
Nuclear extracts of $2.5 \mu \mathrm{g}$ or $0.5 \mu \mathrm{g}$ of either of these antibodies or mouse IgG, and ${ }^{32} \mathrm{P}$-ERE-Oligo $(30,000 \mathrm{cpm}, 1 \mathrm{ng})$ were used in $10 \mu$ l of duplicate binding reactions and incubated for $30 \mathrm{~min}$ at room temperature followed by EMSA analysis. The retarded DNA-protein bands are indicated by the arrows. (C) The similar analysis of duplicate samples of binding reactions with nuclear extracts $(2.5 \mu \mathrm{g})$ of MCF-7 and 21PT cells in the presence of $0.5 \mu \mathrm{g}$ of anti ER-antibodies TE1-11 or SRA 1010 under the conditions described above. These experiments were repeated three times with a different order of additions and preincubations of nuclear extracts, either with antibodies followed by addition of ${ }^{32} \mathrm{P}$-EREoligo or with ${ }^{32} \mathrm{P}$-ERE oligo followed by addition of ER-antibody. All of these experiments showed results similar to those presented here. 


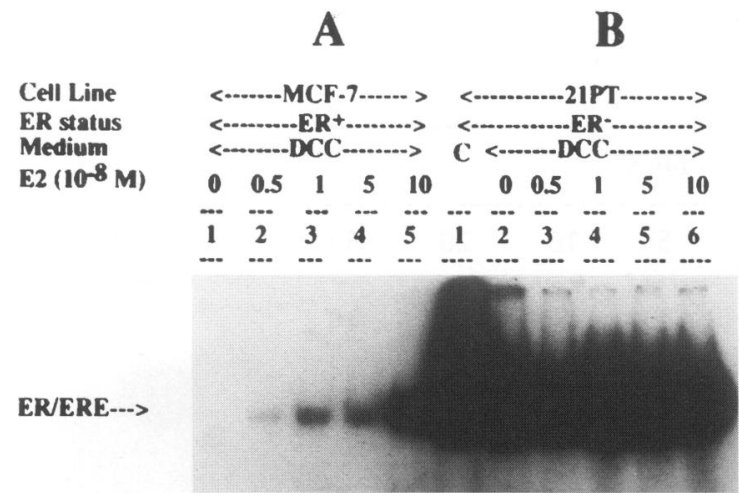

Fig. 5. Hormone dependency of ER-ERE formation. A comparative study of hormone dependency of ER-ERE interaction was investigated with nuclear extracts from MCF-7 (A), 21PT (B), MS (C) and T47D (D) cells. Cells were grown either on stripped medium (DCC, DMEM without phenol red supplemented with $10 \%$ stripped FBS) with indicated concentrations of E2 added for the last $2 \mathrm{hr}$

quence analysis of one of these genes, M6, showed a 95\% homology with Reticulocalbin, a calcium-binding protein of the endoplasmic reticulum $(49,50)$. While this investigation was in progress similar results were reported (51) showing that Reticulocalbin was overexpressed in the more invasive breast cancer cells MDA 435s and at a very low level in MCF-7 cells. All of these results correlated with the E2-dependent and E2-independent ER-ERE interaction observed in MCF-7 and 21PT cells, respectively.

\section{Discussion}

Steroid receptors in general can be classified as hormone-activated transactivators of transcription (2-9). Estrogen (E2) action in target cells is mediated via an initial interaction with the specific receptor ER that initiates downstream events, including interaction with specific motifs (ERE) in the promoter region of classical responsive genes and their transactivation $(4-10,24)$. On the basis of these downstream interactions, this study subclassified several breast cancer cells into two categories-one hormone dependent and responsive to hormone and anti-hormones $\left(\mathrm{ER}^{d}+\right)$, and the other not $\left(\mathrm{ER}^{i}+\right)$. Our study thus identified hormone-independent variants primarily on the basis of the ER interaction with ERE, an independent criterion that is different from that for previously reported ER variants $(18,19,52)$.
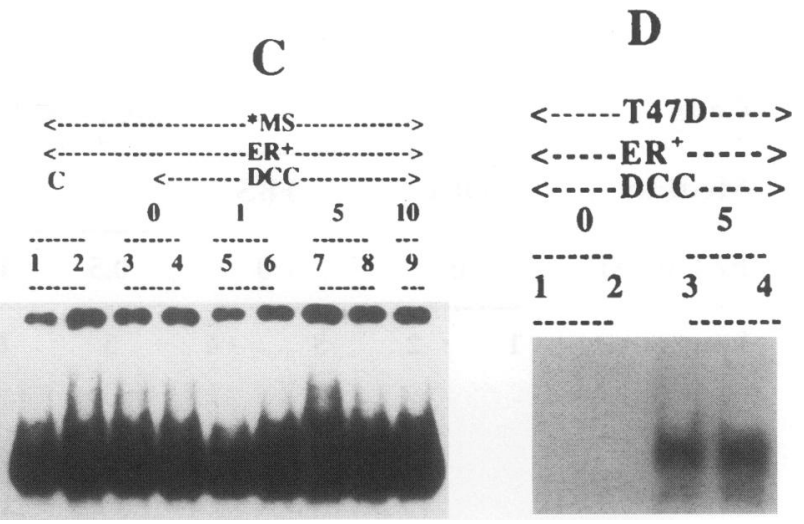

before harvesting, or complete medium (C, DMEM with phenol red and supplemented with $10 \%$ FBS only). Nuclear extracts were prepared and proteinDNA binding reactions were carried out with $2 \mu \mathrm{g}$ of nuclear proteins and ${ }^{32} \mathrm{P}-\mathrm{ERE}$ and incubated at room temperature for 30 min followed by EMSA as described above. The arrow shows the position of the retarded ${ }^{32} \mathrm{P}$-ER-ERE complex.

Although ER could not be detected in the breast cancer cell line 21PT by the ligand-binding assay, ER protein was detected in this cell line by (1) immunofluorescence assay and (2) Western blot analysis. In addition, (3) ER-specific mRNA was detected and (4) ER-specific DNA protein interaction was seen by EMSA. All these criteria characterize $21 \mathrm{PT}$ cells as ER+. The ligand-binding property of ER in these cells appears to be lost. Furthermore, another cell line, MS, which was defined as ER + on the basis of ligand binding, also showed an E2-independent phenotype and thus can be classified as $\mathrm{ER}^{i}+$.

The results presented here demonstrate the hormone-dependent or -independent phenotypes of ER that subclassified these cell lines, irrespective of the mechanisms by which they achieved these ER phenotypes. Hormone-dependent downstream functions of E2, ER-ERE interaction, and transactivation of responsive genes were observed only in the presence of the hormone in the $\mathrm{ER}^{d}+$ subclass, thereby suggesting that E2 is essential for the functional state of ER in these cells. Our inability to detect ER-ERE complex formation from the cytoplasm of E2treated or -untreated cells, and similar observations made previously (9), could be explained by several mechanisms. These include (1) instability of the receptor molecule, (2) the inactive state of ER being complexed with other cellular proteins such as heat shock proteins (53), and (3) preferential compartmentalization of ER.

The hormone-dependent and -independent 
A

Cells

MCF-7 (ER $\left.{ }^{+}\right)$

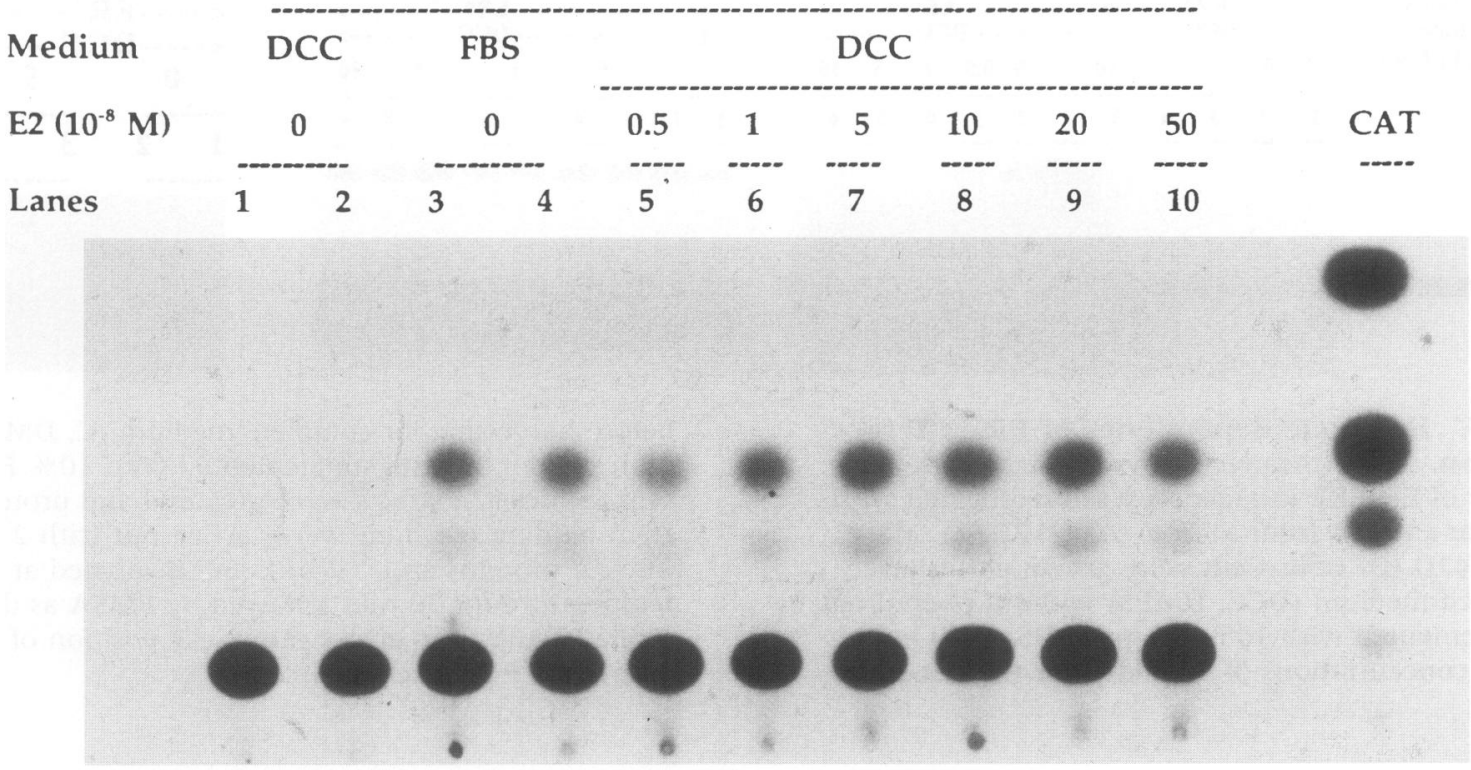

B

\begin{tabular}{|c|c|c|c|c|c|c|c|}
\hline Cells & MCF-7 & & & $1 \mathrm{PT}$ & $\left.R^{\prime}\right)$ & & \\
\hline Medium & DCC I & FBS & & DC & & & \\
\hline E2 $\left(10^{-8} \mathrm{M}\right)$ & 0 & 0 & 0 & 0.5 & 1 & 5 & 10 \\
\hline & $-\cdots$ & $-\cdots$ & $\ldots$ & $\cdots$ & -... & --- & --. \\
\hline Lanes & 1 & 2 & 3 & 4 & 5 & 6 & 7 \\
\hline
\end{tabular}

Fig. 6. Hormone dependency of activation of transfected PS2 promoter. ER+ MCF-7 and ER+ $21 \mathrm{PT}$ cells were grown in $25 \mathrm{ml}$ of complete medium (designated by FBS) in 150-mm tissue culture dishes. After $24 \mathrm{hr}$ the medium was replaced with either complete medium (FBS) or medium containing stripped serum (DCC). Transfection by DEAE dextran of cells with fusion plasmid PS2-CAT (10 $\mu \mathrm{g})$ was as described previously $(20,37)$. Forty-eight hours after transfection the cells were treated with indicated concentrations of E2 and 2 hr later cell extracts were prepared. As controls, cells were also cotransfected with pSV-lacZ. $\beta$-galactosidase activity was the same in the extracts of control and E2treated transfected cells, suggesting that the hormone treatment did not influence an SV40 promoter that lacks the ERE sequence. Panels A and B show the results of transfection experiments with MCF-7 and 21 PT cells, respectively. phenotypes of ER in the transactivation of responsive genes were demonstrated not only with a transfected reporter gene but also with five cellular genes examined by an independent tech- 
nique, further substantiating the hormone-independent phenotype of ER in 21PT cells. The antihormone-sensitive phenotype of the $\mathrm{ER}^{d}+$ cell lines, i.e., MCF-7 and T47D, and the resistant phenotype of another class of cell line, $\left(\mathrm{ER}^{i}+\right)$ 21PT, are also explained by these properties.

That ER is a component of the retarded band in EMSA was established by interactions with anti-ER antibodies. Such antibody-ER interactions with a DNA-protein complex should either generate a larger complex, thereby inducing a supershift, or it can trap ER and make it unavailable for forming the active DNA-binding complex. All the three ER-antibodies tested, irrespective of the epitope map, blocked ER-ERE complex formation as determined by the greatly decreased level of the retarded band in EMSA, thereby establishing the second mechanism. Furlow et al. (54) reported no interference of ERERE complex formation by another ER-specific antibody. This discrepancy may be explained by the differences in the experimental conditions, such as use of a purified ER or different antibody, and using the whole plasmid that carries the ERE elements in the binding reaction in contrast to the native receptor and short oligonucleotides that carry the palindromic ERE used in our studies.

A practical outcome of this strategy of determining ER status is its potential for making therapeutic predictions based on the hormone- and anti-hormone-dependent or independent binding of ER to ERE. The management of breast cancer patients involves routine immunohistochemical determination of ER and PR in tumor tissues as prognostic and therapeutic markers. But the current assays cannot accurately predict the outcome of anti-hormone therapy, the first line of defense. To overcome this difficulty we propose a new approach that uses as a criterion for ER status a downstream functional assay of E2 response in breast tumors, one that is beyond the initial interaction of hormone with its specific receptor. The assessment of ER-ERE complex formation, in addition to E2-ER interaction, should identify most of the spectrum of ER variants in breast tumors. These data also provide a strategy for identifying compounds that inhibit ER-ERE complex formation, which can serve as alternative therapy or part of combination therapy for breast tumors that are resistant to antihormones. Future studies using this assay will determine the frequency of the $\mathrm{ER}^{i}+$ subclass of breast tumors.

\section{Acknowledgments}

The authors are thankful to Drs. Heide L. Ford and Gyongy Molnar for their suggestions and critical evaluation of this study. The work was supported by NIH grant CA61232 and by funds from Massachusetts Department of Public Health, Breast Cancer Research Program.

This manuscript is dedicated to Ruth Sager, geneticist, 1918-1997.

\section{References}

1. Topper J, Freedman C. (1980) Multiple hormone interactions in the development of the mammary gland. Physiol. Rev. 60: 1049-1060.

2. Jensen EV. (1996) Steroid hormones, receptors, and antagonists. Ann. N.Y. Acad. Sci. 784: 1-17.

3. Hedden A, Muller V, Jensen EV. (1995) A new interpretation of antiestrogen action. Ann. N.Y. Acad. Sci. 761: 109-120.

4. Shibata H, Spencer TE, Onate SA, Jenster GJ, Tsai SY, Tsai M-J, O'Malley BW. (1997) Role of coactivators and co-repressors in the mechanism of steroid/thyroid receptor action. Recent Prog. Horm. Res. 52: 141-165.

5. Tsai M-J, O'Malley BW. (1994) Molecular mechanisms of action of steroid/thyroid receptor superfamily members. Annu. Rev. Biochem. 63: 451-486.

6. Kuiper GG, Gustafsson JA. (1997) The novel estrogen receptor-beta subtype: Potential role in the cell- and promoter-specific actions of estrogens and antiestrogens. FEBS Lett. 410: 87-90.

7. Brown M. (1994) Estrogen receptor molecular biology. Hematol. Oncol. North Am. 8: 101-111.

8. Henderson IC. (1991) Endocrine therapy of metastatic breast cancer. In: Harris JR, Hellman S, Henderson IC (eds). Breast Diseases. Lippincott, Philadelphia, pp. 559-603.

9. McDonnell DP, Dana SL, Hoener PA, Lieberman BA, Imhof MO, Stein RB. (1995) Cellular mechanisms which distinguish between hormone- and anti-hormone-activated estrogen receptor. Ann. N.Y. Acad. Sci. 761: 121-137.

10. Evans RM. (1988) The steroid and thyroid hormone receptor superfamily. (1988) Science 240: 889-895.

11. Jensen EV. (1981) Hormone dependency in breast cancer. Breast Cancer Res. Treat. 26: 2319-2326.

12. Scott JA, McGuire WL. (1991) New molecular markers of prognosis in breast cancer. In: Endocrine-Dependent Tumors. Voigt K-D, Knabbe C (eds). Raven Press, New York, pp. 179-196.

13. Witliff JL. (1984) Steroid hormone receptors in breast cancer. Cancer 53: 630-640.

14. Peterson OW, Hoyer PE, Van Deurs B. (1984) Frequency and distribution of estrogen receptor positive cells in normal, nonlactating human breast. Cancer Res. 47: 5748-5751. 
15. Ricketts D, Turnbull L, Ryall G, Bakhshi R, Rawson NSB, Gazet J-C, Nolan C, Coombes RC. (1991) Estrogen and progesterone receptors in the normal female breast. Cancer Res. 51: 1817-1822.

16. Dauvois S, Danielian PS, White R, Parker MG. (1992) Anti-estrogen ICI 164,384 reduces cellular estrogen receptor content by increasing its turnover. Proc. Natl. Acad. Sci. U.S.A. 89: 4037-4041.

17. Rio MC, Bellocq JP, Gairard B, Rasmussen UB, Krust A, Koehl C, Calderoli H, Schiff V, Renaud R, Chambon P. (1987) Specific expression of the PS2 gene in subclasses of breast cancers in comparison with expression of the estrogen and progesterone receptors and the oncogene ERBB2. Proc. Natl. Acad. Sci. U.S.A. 84: 9243-9247.

18. Fuqua SAW, Chamness GC, McGuire WL. (1993) Estrogen receptor mutations in breast cancer. J. Cell. Biochem. 51: 135-139.

19. Zhang Q-X, Borg A, Wolf DM, Oesterreich S, Fuqua SAW. (1997) An estrogen receptor mutant with strong hormone-independent activity from metastatic breast cancer. Cancer Res. 57: 12441249.

20. Reese JC, Katzenellenbogen BS. (1992) Examination of the DNA-binding ability of estrogen receptor in whole cells: Implications for hormone-independent transactivation and the actions of anti-estrogens. Mol. Cell. Biol. 12: 4531-4538.

21. Leygue ER, Watson PH, Murphy LC. (1996) Estrogen receptor varients in normal human mammary tissue. J. Natl. Cancer Inst. 88: 284-290.

22. Gotteland M, Desauty G, Delarue JC, Liu L, May E. (1995) Human estrogen receptor messenger RNA variants in both normal and tumor breast tissues. Mol. Cell. Endocrinol. 112: 1-13.

23. Nicholson RI, Gee JMW, Manning DL, Wakeling AE, Montano MM, Katzenellenbogen BS. (1995) Response to pure anti-estrogens (ICI164,384, ICI 182,780 ) in estrogen sensitive and resistant experimental and clinical breast cancer. Ann. N.Y. Acad. Sci. 761: 148-163.

24. Kumar V, Chambon P. (1988) The estrogen receptor binds tightly to its responsive element as a ligand-induced homodimer. Cell 55: 145-156.

25. Zwijsen RML, Wientjens E, Klompmaker R, Sman JV-D, Bernards R, Michalides JAM. (1997) CDKindependent activation of estrogen receptor by cyclin D1. Cell 88: 405-415.

26. Neuman E, Ladha MH, Lin N, Upton TM, Miller SJ, DiRenzo J, Pestell RG, Philip HW, Dowdy SF, Brown M, Ewen ME. (1997) Cyclin Dl stimulation of estrogen receptor transcriptional activity independent of cdk4. Mol. Cell. Biol. 17: 53385347.

27. Smith CL, Connely M, O'Malley BW. (1993) Modulation of the ligand-independent activation of the human estrogen receptor by hormone and anti-hormone. Proc. Natl. Acad. Sci. U.S.A. 90: 6120-6124.
28. Hanstein B, Eckner R, DiRenzo J, Halamachi S, Liu H, Searchy B, Kurokawa R, Brown M. (1996) p300 is a component of an estrogen receptor complex. Proc. Natl. Acad. Sci. U.S.A. 93: 11540-1 1545.

29. Halachmi S, Marden E, Martin G, Mackay H, Abbondanza C, Brown M. (1994) Estrogen receptorassociated proteins: Possible mediators of hormone induced transcription. Science 264: 14551458.

30. Kraus WL, Weis KE, Katzenellenbogen BS. (1995) Inhibitory cross-talk between steroid receptors: Differential targeting of estrogen receptor in the repression of its transcriptional activity by agonistand antagonist-occupied progestin receptors. Mol. Cell. Biol. 15: 1847-1857.

31. Yang NN, Venugopalan M, Hardikar S, Glasebrook A. (1996) Identification of an estrogen response element activated by metabolites of $17 \beta$-estradiol and raloxifene. Science 273: 1222-1225.

32. Sukovich DA, Mukherjee R, Benfield, PA. (1994) A novel cell-type-specific mechanism for estrogen receptor-mediated gene activation in the absence of an estrogen-responsive element. Mol. Cell. Biol. 14: 7134-7143.

33. Kuiper GG, Enmark E, Pelto-Huikko M, Nilsson S, Gustafsson J-A. (1996) Cloning of a novel estrogen receptor expressed in prostate and overy. Proc. Natl. Acad. Sci. U.S.A. 93: 5925-5930.

34. Vladusic EA, Hornby AE, Guerra-Vladusic FK, Lupu, R. (1998) Expression of estrogen receptor $\beta$ messenger RNA variant in breast cancer. Cancer Res. 58: $210-214$.

35. Schodin DJ, Zhuang Y, Shapiro DJ, Katzenellenbogen BS. (1995) Analysis of mechanisms that determine dominant negative estrogen receptor effectiveness. J. Biol. Chem. 270: 31 163-31171.

36. Berry M, Nunez A-M, Chambon P. (1989) Estrogen responsive element of the PS2 gene is an imperfect palindromic sequence. Proc. Natl. Acad. Sci. U.S.A. 86: 1218-1223.

37. Klein-Hitpass L, Tsai SY, Greene GL, Clark JH, Tsai M-J, O'Malley BW. (1989) Specific binding of estrogen receptor to the estrogen response element. Mol. Cell. Biol. 9: 43-49.

38. Sager R, Sheng S, Anisowicz A, Sotiropoulou G, Zou Z, Stenman G, Swisshelm K, Chen Z, Hendrix MJC, Pemberton P, Rafidi K, Ryan K. (1994) RNA genetics of breast cancer: Maspin as a paradigm. Cold Spring Harb. Symp. Quant. Biol. 59: 537547.

39. Zajchowski DA, Band V, Trask DK, Kling D, Connolly JL, Sager, R. (1990) Suppression of tumorforming ability and related traits in MCF-7 human breast cancer cells by fusion with immortal mammary epithelial cells. Proc. Natl. Acad. Sci. U.S.A. 87: 2314-2318.

40. Dignam JD, Lebovitz RM, Roeder RD. (1983) Accurate transcription initiation by RNA polymerase II in a soluble extract from isolated mammalian nuclei. Nucl. Acids Res. 11: 1475-1489. 
41. Biswas DK, Ahlers CM, Dezube BJ, Pardee AB. (1993) Cooperative inhibition of NF-kB-Tat-induced superactivation of human immunodeficiency virus type 1 long terminal repeat. Proc. Nat. Acad. Sci. U.S.A. 90: 11044-1 1048.

42. Biswas DK, Salas TR, Wang F, Ahlers CM, Dezube BJ, Pardee AB. (1995) A Tat-induced auto-upregulatory loop for superactivation of the human immunodeficiency virus type-1 promoter. J. Virol. 69: 7437-7444.

43. Harlow E, Lane D. (1988) In: Antibodies, A Laboratory Manual. Cold Spring Harbor Laboratory, Cold Spring Harbor, NY, pp. 392-397.

44. Ausubel FM, Brent R, Kingston RE, Moore DD, Seidman JG, Smith JA, Struhl K. (1994) DNAprotein interactions: Rapid separation of protein-bound DNA from free DNA using nitrocellulose filters. In: Chodash LA (ed). Current Protocols in Molecular Biology. Current Protocols, John Wiley \& Sons, Inc., New York, pp. 12.8.112.8.5.

45. Liang P, Pardee AB. (1992) Differential display of eukaryotic messenger RNA by means of the polymerase chain reaction. Science 257: 967-971.

46. Martin K, Kwan C-P, Sager R. (1997) A directsequencing-based strategy for identifying and cloning cDNAs from differential display gels. In: Pardee AB, Liang $\mathrm{P}$ (eds). Methods in Molecular Biology. Differential Display: Methods and Applications. Humana Press, Totowa, NJ, pp. 77-85.

47. Altschul SF, Gish W, Miller W, Myers EW, Lipman DJ. (1990) Basic local alignment search tool. $J$. Mol. Biol. 215: 403-410.

48. Martin K, Kwan C-P, O'Hare MJ, Pardee AB, Sager S. (1998) Identification and verification of differential display cDNAs using gene-specific primers and hybridization arrays. Cancer Res. Techniques 24: 1018-1026.

49. Ozawa M. (1995) Structure of the gene encoding mouse reticulocalbin, a novel endoplasmic reticulum-resident $\mathrm{Ca}(2+)$-binding protein with multiple EF-hand motifs. J. Biochem. (Tokyo) 118: 154160.

50. Scherer PE, Lederkremer GZ, Williams S, Fogliano M, Baldini G, Lodish HF. (1996) Cab45, a novel $(\mathrm{Ca} 2+)$-binding protein localized to the Golgi lumen. J. Cell. Biol. 133: 257-268.

51. Liu Z, Brattain MG, Appert H. (1997) Differential display of reticulocalbin in the highly invasive cell line, MDA-MB-435s, versus the poorly invasive cell line, MCF-7. Biochem. Biophys. Res. Commun. 231: 283-289.

52. Fuqua SAW, Fitzgerald SD, Chamness GC, Tandon AK, Mcdonnell DP, Nawaz Z, O'Malley BW, McGuire WL. (1991) Variant human breast tumor estrogen receptor with constitutive transcriptional activity. Cancer Res. 51: 105-109.

53. Allan GF, Leng X, Tsai SY, Weigel NL, Edwards DP, Tsai M-J, O'Malley BW. (1992) Hormone and antihormone induce distinct conformational changes which are central to steroid receptor activation. J. Biol. Chem. 267: 19513-19520.

54. Furlow DJ, Murdoch FE, Gorski J. (1993) High affinity binding of estrogen receptor to a DNA response element does not require homodimer formation or estrogen. J. Biol. Chem. 268: 1251912525.

55. Mosman T. (1983) Rapid colorimetric assay for cellular growth and survival: Application to proliferation and cytotoxic assay. J. Immunol. Methods 65: 55-64. 